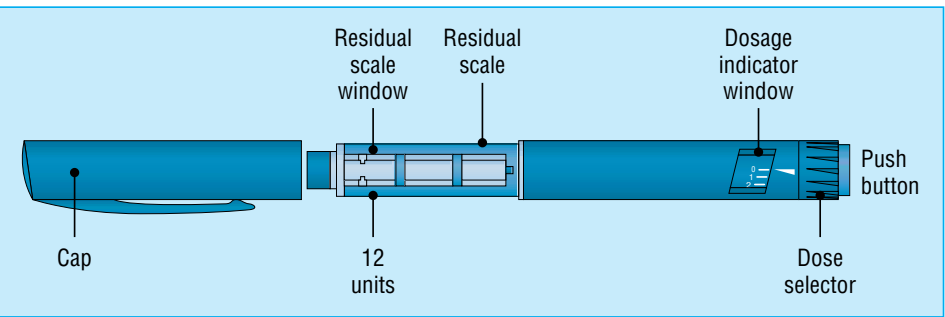

Fig 2 To administer insulin with the FlexPen, the dose is measured by dialling the appropriate number of units on the dose selector. The button is pushed to expel insulin via a needle attached to the clear barrel of the device. "Reverse dialling" of the dose selector does not expel insulin understanding and a reminder that the described technique is the only safe way to use the injection device. Similarly, injection technique should be reviewed carefully in all patients presenting with diabetic ketoacidosis. In addition, we recommend that warnings about the hazards of incorrect injection technique should be included in the information about all insulin pen devices.

We thank J Scanlon and E Grocott for allowing us to report these cases and NovoNordisk (UK) for permission to use the diagram (adapted) for figure 2.

Contributors: VRB and NM wrote the first draft. EI and EH identified reverse dialling as the cause of the recurrent diabetic ketoacidosis. All authors contributed to the management of the patients and to the final draft of the manuscript. DJ is guarantor. Funding: None

Competing interests: None declared. NovoPen 3 device had resulted in insulin injection. Both patients had mistakenly assumed that the same technique would deliver insulin from the FlexPen. We suspect that other patients may try this reverse dialling technique, potentially compromising glycaemic control and running the risk of diabetic ketoacidosis. We have informed the Medicines and Healthcare Products Regulatory Agency of this issue.

Non-specialist staff did not recognise faulty injection technique as the cause of hyperglycaemia and ketosis, resulting in searches for occult infection and suspicion of non-adherence to insulin therapy. Adequate instruction is essential for all patients whose injection devices are changed. This education should include direct observation of an injection to ensure full
1 Krentz A, Nattrass M. Acute metabolic complications of diabetes: diabetic ketocidosis, hyperosmoler non-ketotic hyperglycaemia and lactic acidosis. In: Pickup JC, Williams G. Textbook of diabetes 1. 3rd edn. Oxford: sis. In: Pickup

2 Dunger DB, Sperling MA, Acerini CL, Bohn DJ, Daneman D, Danne TP, et al. European Society for Paediatric Endocrinology/Lawson Wilkins Pediatric Society consensus statement on diabetic ketoacidosis in children and adolescents. Pediatrics 2004;113:e133-e140.

3 Basu A, Close CF, Jenkins D, Krentz AJ, Nattrass M, Wright AD. Persisting mortality in diabetic ketoacidosis. Diabet Med 1993;10:282-4.

American Diabetes Association. Hyperglycemic crises in diabetes. Diabe tes Care 2004;27:S94-102.

5 Department of Health. National service framework for diabetes: delivery strategy. London: DoH, 2002.

(Accepted 2 February 2006)

\section{A cautionary tale}

Hospital acquired infection has a nasty habit of striking just as the patient is getting better. This is never more apparent than on elderly care wards, where vulnerable patients often require a period of rehabilitation.

During my four months as a senior house officer on an elderly care ward, I was particularly careful to clean my hands between patients, and to this end each bed was fitted with a bottle of alcohol gel. New arrivals on the ward could be forgiven for feeling surprised by each doctor's display of enthusiasm as he or she approaches with a smile and a vigorous rubbing of hands, and puzzled by the smell of alcohol not dissimilar to gin.

On one occasion, however, it was I who was puzzled by an odour not dissimilar to gin emanating from within the curtains surrounding the next bed on my ward round. Inside sat a dishevelled, bearded, tattooed, and sporadically pierced man in his mid-40s, whom I later learnt was well known to the gastroenterology ward. He had been found unconscious in a bus shelter after a drinking binge and was unable to walk because of a deterioration of his peripheral neuropathy. His usual spot on the gastroenterology ward was occupied, so he had been admitted to our elderly care ward for rehabilitation.

I started him with the usual vitamin B and chlordiazepoxide, and he seemed genuinely desperate to stop drinking so that his legs might recover. Over the next few days, Sister and her team set to work on him, and when she proudly drew back the curtains to bed 4 on the following ward round we barely recognised the bewildered but exceptionally well groomed man before us. The dose of chlordiazepoxide was gradually reduced, he received some physiotherapy, and things were going well until one night he became inexplicably disinhibited and ataxic.
On examination he was obviously intoxicated, yet he had not left the ward and had received no visitors. After much head scratching and a thorough search of his bed space, Sister returned triumphantly brandishing a battered water bottle into which had been decanted a generous dose of our finest $60 \%$ ethanol hand-cleaning gel. Our patient was allowed to sober up and was supported with some intravenous saline, but was eventually discharged unceremoniously after a day or two on the gastroenterology ward (where he somehow managed to repeat the episode).

With hindsight and a little lateral thinking it is clear that, as on the paediatric wards, we should attach the dispensers of hand-cleaning gel to the staff rather than to the patients' beds. Perhaps manufacturers should add a foul tasting substance. On a single specialty ward one gets accustomed to a set of commonly recurring problems, and it is easy to fall into the trap of thinking that what works for one patient will work equally well for another. I had not considered that, although alcohol gel protects most of the patients on our ward from hospital acquired infection, it represents a hazard for confused patients, alcoholics, and children.

James Burge senior house officer, Royal Dewon and Exeter NHS Trust,Exeter (jamesaburge@yahoo.co.uk) With contribution from Jane Sword, consultant elderly care physician, Royal Devon and Exeter NHS Trust.

We welcome articles up to 600 words on topics such as A memorable patient, A paper that changed my practice, My most unfortunate mistake, or any other piece conveying instruction, pathos, or humour. Please submit the article on http://submit.bmj.com Permission is needed from the patient or a relative if an identifiable patient is referred to. 